\title{
Effect of Weight Change on Economic Outcomes Among Persons with Type 2 Diabetes Mellitus in the United States: Beyond Glycemic Control
}

Swapna Karkare, MS; Moshe Fridman, PhD; Tam Dang-Tan, PhD; Jingsong Lu, MS; B. Gabriel Smolarz, MD, MS, FACE; Mitch DeKoven, MHSA; and Neeraj N. Iyer, PhD

\begin{abstract}
BACKGROUND: Previous studies report weight loss to be associated with significantly lower total health care costs among patients with type 2 diabetes mellitus (T2DM). The effect of weight change on health care costs, independent of glycemic control and after controlling for time-varying covariates among T2DM patients, remains unknown.
\end{abstract}

OBJECTIVE: To evaluate the effect of weight change, independent of glycemic control, on all-cause and T2DM-related health care resource utilization (HCRU) and costs among T2DM patients in the United States.

METHODS: A retrospective cohort study was conducted using a linked data extract composed of IQVIA's RWI Data Adjudicated Claims-US and Ambulatory Electronic Medical Record data. Adults (aged $\geq 18$ years) with T2DM receiving $\geq 1$ oral antidiabetic drug (OAD) medication, glucagon-like peptide-1 receptor agonist (GLP-1RA), and/or short- or long-acting insulin between January 1, 2010, and December 31, 2014 were included (the date of the first observed medical claim with a diagnosis code or medication prescription claim was the index date). Baseline characteristics were evaluated in the 6 -month pre-index period. Weight loss $(3 \%, 5 \%$, or $7 \%$ from baseline) was evaluated over two 6-month periods (months 1-6 and 7-12) following the index date. Covariates included time-varying weight, hemoglobin A1c (A1c), costs, and HCRU within each 6-month period. Outcomes of interest (all-cause and T2DM-related HCRU and costs) were evaluated in the 6-month (months 13-18) and 12-month (months 13-24) periods following the initial 1- to 6-month and 7- to 12-month post-index periods. Structural nested mean models were used to evaluate the effect of weight change on these outcomes, independent of glycemic control.

RESULTS: 1,407 patients were included (mean age $=55$ years; $55 \%$ male), with a mean baseline weight of $102.2 \mathrm{~kg}$ (median $=99.7 \mathrm{~kg}$ ) and a mean baseline A1c of $7.4 \%$ (median $=6.9 \%$ ). In adjusted analysis, weight loss was associated with significantly lower all-cause and T2DM-related annual total health care costs. Compared with those showing no weight change, a $3 \%, 5 \%$, and $7 \%$ weight loss resulted in approximately $\$ 500, \$ 800$, and $\$ 1,100$ in savings, respectively, in all-cause annual total health care costs per patient in the year following the weight loss. Similarly, compared with those with no weight change, a $3 \%, 5 \%$, and $7 \%$ weight loss resulted in approximately $\$ 200, \$ 300$, and $\$ 400$ in savings, respectively, in T2DMrelated annual total health care costs per patient in the following year. Even greater savings (up to $\sim \$ 2,000$ and $\sim \$ 800$ in all-cause and T2DM-related annual costs per patient, respectively) were experienced by those who lost weight compared with those who gained weight.

CONCLUSIONS: After accounting for glycemic control, this study found that weight loss was associated with additional significant reductions in allcause and T2DM-related annual total health care costs. Understanding the role of weight loss in T2DM may provide useful evidence for decision makers as they evaluate therapy options for T2DM.

J Manag Care Spec Pharm. 2019;25(6):658-68

Copyright $\odot 2019$, Academy of Managed Care Pharmacy. All rights reserved.

\section{What is already known about this subject}

More than $80 \%$ of patients with diabetes are either overweight or living with obesity.

Weight loss is associated with improvements in quality of life and glycemic control and decreases in cardiovascular risk factors among patients with type 2 diabetes mellitus (T2DM).

Results from the few studies that have evaluated the effect of weight change on health care costs beyond glycemic control among T2DM patients have indicated that weight loss is associated with significantly lower health care costs.

\section{What this study adds}

This study evaluated the effect of weight change, independent of glycemic control, on all-cause and T2DM-related health care resource utilization and costs among patients with T2DM in the United States, after controlling for time-varying confounders.

A greater magnitude of weight loss resulted in greater cost savings. Irrespective of the pattern in which weight loss occurred over the study period, losing weight was associated with significant reductions in all-cause and T2DM-related annual total health care costs

A s of 2015, the prevalence of diabetes in the United States was an estimated 30.3 million (9.4\% of the total U.S. population). ${ }^{1}$ Diabetes-related health care expenditures in the United States were \$327 billion in 2017 (U.S. dollars), with $73 \%$ ( $\$ 237$ billion) attributed to diabetes-related direct health care expenditures and 27\% (\$90 billion) attributed to decreases in productivity. ${ }^{2}$ It is reported that, after controlling for age and gender, patients with diabetes incur 2.3 times greater annual health care expenditures compared with those without diabetes. ${ }^{3}$ The majority of these medical expenditures can be attributed to hospital inpatient visits and medication utilization (other than insulin and other antidiabetic agents). ${ }^{2,4}$

Weight reduction is important for prevention and management of type 2 diabetes mellitus (T2DM). ${ }^{5}$ Excess adiposity leading to insulin resistance is the major risk factor for T2DM. ${ }^{1,6}$ The Centers for Disease Control and Prevention reported that between 2011 and 2014, 87.5\% of adults (aged $\geq 18$ years) 
with diabetes in the United States were overweight or living with obesity, with $26.1 \%$ being overweight (body mass index [BMI] $>25.0$ and $\left.<30.0 \mathrm{~kg} / \mathrm{m}^{2}\right), 43.5 \%$ being obese $(\mathrm{BMI} \geq 30$ to $<40.0 \mathrm{~kg} / \mathrm{m}^{2}$ ), and $17.8 \%$ being severely obese (BMI $\geq 40 \mathrm{~kg} /$ $\mathrm{m}^{2}$ ). ${ }^{1}$ Since obesity deteriorates the control of hemoglobin Alc, blood pressure, and cholesterol among patients with diabetes, patients having both obesity and diabetes are at an increased risk for developing microvascular and macrovascular morbidity and mortality. ${ }^{7-9}$ Thus, having excess weight significantly increases the clinical and economic burden of diabetes.

Diabetes treatment guidelines emphasize the paramount importance of weight loss among overweight and obese T2DM patients and highlight that even a relatively modest 5\%-10\% (but consistent) weight loss helps manage glycemic control among these patients. ${ }^{6,10-12}$ It is reported that patients with moderate weight loss $(5 \%$ to $<10 \%)$ are more likely to achieve reductions in Alc, blood pressure, C-reactive protein, lowdensity lipoprotein cholesterol, and triglyceride levels (cardiovascular disease risk factors) compared with patients with stable weight, and greater weight loss results in greater clinical improvements. ${ }^{12,13}$ The effect of weight change on clinical outcomes among patients with T2DM is well established in the literature. Weight loss is associated with improvements in quality of life; glycemic control and blood pressure; and reductions in cardiovascular risk factors, mortality, and diabetes complications. ${ }^{14-20}$

A few studies have evaluated the association between weight changes and health care costs among patients with T2DM.21-28 Results from these studies have generally indicated that weight loss is associated with significantly lower costs. However, these studies have several limitations. Most of these studies measure weight change in the initial 6-month period and then evaluate the effect of this weight change on costs in the subsequent 1-year period. Studies either assume weight change patterns or the timing of weight change to be consistent for all patients during the follow-up period or that weight changes during the follow-up period do not significantly affect health care costs in the follow-up period. These assumptions make it difficult to evaluate the true long-term effect of weight changes on costs. Although several weight change patterns over time in a real-world setting have been reported in the literature, studies on the associations between weight change and costs have used static designs using single measurements of weight and outcomes. ${ }^{21,22,24-26,28,29}$ Few studies have accounted for weight change patterns that are commonly observed in a real-world setting, including the ubiquitously observed weight gain over time. ${ }^{27}$ Previous studies also inadequately account for timevarying covariates (e.g., glycemic control and age) and do not focus on the effect of weight change patterns incremental to glycemic control.

The goal of this study was to evaluate the effect of weight change, independent of glycemic control, on all-cause and
T2DM-related health care resource utilization (HCRU) and costs among patients with T2DM in the United States. A secondary objective was to evaluate whether patterns or timing of weight change had any effect on all-cause and T2DM-related HCRU and costs. This study will help link weight change to outcomes that matter to health care decision makers and may provide additional evidence to evaluate therapy options for T2DM.

\section{Methods}

\section{Data Source}

This retrospective cohort study was conducted using a linked data extract developed by using IQVIA's RWI Data Adjudicated Claims-US and Ambulatory Electronic Medical Record (EMR) database from January 1, 2010, through December 31, 2014. A deterministic matching algorithm was used to link patient data across the 2 databases. All data were compliant with the Health Insurance Portability and Accountability Act to protect patients' privacy. Most of the patients in the database have commercial insurance through preferred provider organization (PPO) plans.

\section{Claims-Based Inclusion/Exclusion Criteria}

Patients were initially included in the study if they had evidence of $\geq 2$ medical visit encounter diagnosis codes for T2DM or evidence of $\geq 1$ diagnosis code for T2DM and use of oral antidiabetic drugs (OADs) or glucagon-like peptide-1 receptor agonists (GLP-1RAs), with at most one type 1 diabetes mellitus (TIDM) code that could appear only once per day between January 1, 2010, and December 31, 2014. The date of the first observed medical claim with a diagnosis code or medication prescription claim was defined as the index date. Subsequently, among patients excluded using the above criteria, an additional inclusion criterion was applied: evidence of insulin use only plus greater number of T2DM codes than T1DM codes in the 6-month pre-index period. For inclusion, patients needed to be aged $\geq 18$ years at the index date, with continuous health plan enrollment for $\geq 180$ days immediately preceding the index date (6-month pre-index period) and $\geq 720$ days immediately following the index date (24-month post-index period).

Patients were excluded from the study if they had evidence of $\geq 1$ diagnosis/procedure code for gestational diabetes, bariatric surgery, pregnancy, total pancreatic failure, acute or chronic pancreatitis, stage 5 end-stage renal disease, dialysis/ renal replacement therapy, feeding difficulty, liver cirrhosis, cancer, or malignancy at any time during the study period; had data quality issues (aged $\geq 65$ years at the index date and not covered by Medicare Risk due to incomplete Medicare fee-for-service data; Medicare Risk or Medicare Advantage is offered by private commercial health plans as an alternative to traditional Medicare); or had Medicare cost coverage or State Children's Health Insurance Program coverage; or had invalid year of birth, gender, or health plan enrollment dates. 


\section{Linkage to EMR and Inclusion/Exclusion Criteria}

Patients linkable to the EMR database were then identified. A deterministic matching algorithm was used to link patients between both the databases that used patient information including first name, last name, gender, date of birth, and ZIP code to ensure continuity of patient records across datasets. Patients were additionally required to have $\geq 1$ weight measurement or $\geq 1$ BMI and height value (to calculate weight) in the 6 -month period before the index date (baseline weight) and at any point in time during the 1- to 6-month and 7- to 12-month periods after the index date. Patients were also required to have $\geq 1$ Alc measurement in the 6-month pre-index period (baseline Alc) and at any point during the 1- to 6-month and 7- to 12 -month periods after the index date. To remove outliers, patients with $>15 \%$ weight loss for any 6 -month period or with $>25 \%$ weight loss for the 12-month cumulative period or with $>20 \%$ weight gain for any 6 -month period or with $>30 \%$ weight gain for the 12-month cumulative period were excluded from the study sample.

Among patients with $>1$ baseline weight measurement available, the weight measurement closest to the index date was considered as the baseline weight. Among patients with $>1$ weight measurement available in months 1-6 and 7-12 after the index date, the weight measurement closest to the end of each of the 6-month intervals was considered as the post-index weight. Similar rules were applied among patients with $>1$ baseline Alc measurement available.

\section{Patterns of Weight Change}

For this study, weight loss (3\%, 5\%, or 7\%) was evaluated over two 6-month periods (1-6, 7-12) following the index date..$^{20,23-25}$ For example, among patients with 3\% weight loss in the initial 12-month period, 3 different patterns of weight loss representing different timing of weight loss were evaluated: (1) lose the entire 3\% weight in the 1- to 6-month post-index period, or (2) lose the entire 3\% weight in the 7 - to 12 -month post-index period, or (3) lose $1.5 \%$ weight in the 1 - to 6 -month post-index period and the remaining $1.5 \%$ weight in the 7 - to 12 -month post-index period (i.e., cumulative weight loss of 3\% over 12 months). Similar patterns were assessed for patients with $5 \%$ and $7 \%$ weight loss.

\section{Outcomes of Interest}

All-cause and T2DM-related (defined as claims for antihyperglycemic agent pharmacy, blood glucose test strips, and medical claims with a diagnosis for T2DM at any position for outpatient claims/primary diagnosis on discharge claim for hospitalizations) HCRU and costs were evaluated in the 6-month (months 13-18 post-index) and 12-month periods (months 13-24 post-index) following the 7- to 12 -month post-index period. HCRU was reported for mutually exclusive pharmacy services, outpatient visits, emergency department (ED) visits, and inpatient visits. Direct health care costs for services covered by the patient's insurance benefit were reported, using the allowed amount on the claim, which represents the contracted reimbursable amount for covered medical services or supplies that the health plan agrees to pay to service providers. Costs were converted to 2016 U.S. dollars using the medical care component of the Consumer Price Index. Study time periods are shown in the Appendix (available in online article).

Patient demographic and clinical characteristics were obtained as of the 6-month pre-index period from the integrated dataset. These included age at index date, gender, region, health plan type, payer type, index year, physician specialty at index, Charlson Comorbidity Index (CCI) score (excluding diabetes [both TIDM and T2DM] as it was the exposure of interest), Adapted Diabetes Complications Severity Index score, comorbidities of interest, pre-index use of antidiabetic classes, concomitant medications, number of pre-index antidiabetic classes used, BMI, weight, and Alc. ${ }^{30,31}$ All-cause and T2DM-related HCRU and costs incurred in the 6-month pre-index period were also reported.

\section{Statistical Analysis}

For categorical measures, data were reported as the frequency (number of cases) and percentage of total patients observed in each category. For continuous variables, data were reported as the mean, standard deviation (SD), and median. Differences in the distribution of these variables were tested for statistical significance using the chi-squared test for categorical variables and the nonparametric Wilcoxon rank-sum test for continuous variables. A $P$ value of $\leq 0.05$ was considered statistically significant. SAS version 9.3 (SAS Institute, Cary, NC) was used for all statistical analyses.

Structural nested mean models (SNMMs) were used to evaluate the effect of time-varying covariates (weight and Alc) affected by patient baseline characteristics on outcomes of interest (all-cause and T2DM-related HCRU and costs). ${ }^{32}$ SNMM enables estimation of the effect of weight change at each time point ("j") on end-of-study costs and HCRU outcomes as a function of the history of Alc and cost values through time j-1. The model allows for the potential time-varying causal effect of weight change on end-of-study cost to be moderated by Alc, as may be expected from the temporal effect of glycemic control on weight changes. By conditioning on the history of timevarying covariates, the average effect of weight changes over time on outcomes can be estimated while taking into account changing patterns in the time-varying covariates.

A 6-month pre-index period was used to gather baseline information. Two 6-month periods (1-6, 7-12) after the index date were used to measure time-varying weight and Alc, as well as costs and HCRU within each 6-month period. This allowed measuring the patterns of change for weight and Alc. This 1-year period was defined as the evaluation period. 
Six-month (13-18 months post-index) and 12-month periods (13-24 months post-index) after the first one-and-a-half years of baseline and evaluation periods were used to assess all-cause and T2DM-related HCRU and costs. The 2 outcome periods ( 6 months and 12 months) were necessary to allow for (a) a closer, more immediate effect of the time-varying covariates on HCRU and cost (6 months), and (b) a longer-term effect of 12 months that is more likely to capture ED visits or hospitalizations.

SNMMs estimated all-cause and T2DM-related HCRU and costs for those showing weight loss $(3 \%, 5 \%$, or $7 \%$ weight loss in 1-6 months and/or 7-12 months post-index period) compared with those who gained weight $3.5 \%$ weight gain in the 1- to 6-month period and another 3.5\% weight gain in the 7- to 12-month post-index period). Similarly, costs and resource use differences were also estimated for those who lost weight compared with those showing no weight change.

\section{Results}

\section{Study Sample}

A total of 3,921,667 patients with T2DM were initially identified in the IQVIA RWI Data Adjudicated Claims-US database. After applying the inclusion and exclusion criteria, a total of 1,407 patients $(0.04 \%)$ were available for analyses (Figure 1 ). Patients were excluded primarily due to the following criteria: lack of continuous enrollment in the database to obtain required data points (67.4\%), not linkable to EMR database (22.3\%), evidence of exclusionary diagnoses/procedures of interest (6.7\%), no BMI and Alc measurements in the 6-month pre-index period and in 1- to 6-month and 7- to 12-month post-index periods $(2.5 \%)$, data quality issues $(0.7 \%)$, aged $<18$ years at index $(0.4 \%)$, and extreme weight loss or weight gain (0.001\%).

\section{Baseline Characteristics of the Study Sample (6-Month Pre-Index Period)}

Mean age of all patients was 55.2 years (median $=56.0$ years) and approximately half were male (55.2\%). The majority of these patients were covered under the PPO health plan type (72.6\%), and half of them resided in the Northeast U.S. census region (52.4\%). Mean CCI score (excluding TIDM and T2DM) of all patients was 0.3 (median=0.0) and two thirds of these patients had comorbid dyslipidemia/hypertriglyceridemia (62.3\%) and hypertension (60.6\%). The majority of these patients used all-cause prescription services (91.6\%) and had $\geq 1$ all-cause outpatient visit (98.4\%) in the baseline period. Mean baseline all-cause and T2DM-related total health care costs were $\$ 4,228$ and $\$ 550$, respectively. Refer to Tables 1,2 , and 3 for additional details.

\section{Effect of Weight Loss on All-Cause and T2DM-Related Costs and HCRU in the Short Term (6-Month Follow-up)}

During the 6-month follow-up period (i.e., 13-18 months post-index), mean all-cause and T2DM-related total health care costs of the study sample were $\$ 5,043$ (prescription services $=\$ 1,578$; ED costs $=\$ 125$; inpatient costs $=\$ 1,011$; outpatient costs $=\$ 2,329$ ) and $\$ 1,211$ (prescription services $=\$ 471$; ED costs $=\$ 62$; inpatient costs $=\$ 3$; outpatient costs $=\$ 675$ ), respectively (Table 3 ). After controlling for changes in timevarying covariates using SNMMs, weight loss was associated with significantly 6\%-13\% lower T2DM-related total health care costs (cost ratio $[C R]=0.87-0.94 ; P=0.0015$ ) among patients with $1.5 \%, 2.5 \%$, and $3.5 \%$ weight loss in each of the 1- to 6-month and 7-to 12-month post-index periods, resulting in $\sim \$ 72, \$ 118$, and $\$ 162$ in savings, respectively, versus no weight change. As expected, greater magnitude of weight loss resulted in greater savings. T2DM-related total health care costs were $18 \%-26 \%$ lower $(C R=0.74-0.82 ; P=0.0015)$ among patients with weight loss versus weight gain $(3 \%, 5 \%$, and $7 \%$ weight loss resulted in $\sim \$ 224, \$ 264$, and $\$ 302$ in savings, respectively vs. those who gained weight). Weight loss did not affect all-cause total health care costs or prescription, inpatient, $\mathrm{ED}$, and outpatient costs in the short term (Table 4).

During the 6-month follow-up period, the majority of T2DM patients used prescription services (all-cause $=95.7 \%$; T2DMrelated $=74.1 \%$ ) and had $\geq 1$ outpatient visit (all-cause $=97.2 \%$; T2DM-related $=84.5 \%$; refer to Table 2 for additional details). After controlling for changes in time-varying confounders including Alc using SNMM, weight loss was associated with a significant effect on all-cause ED and outpatient visits in the short term. ED visits were 6\%-14\% higher among patients with $3 \%, 5 \%$, and $7 \%$ weight loss (visit ratio $[\mathrm{VR}]=1.06-1.14$; $P<0.05)$ versus no weight change and $23 \%$ higher among patients with $7 \%$ weight loss $(V R=1.23 ; P=0.04)$ versus weight gain in the 1- to 6-month post-index period. Outpatient visits in the short term were 5\%-12\% lower among patients with 3\%, $5 \%$, and $7 \%$ weight loss or a cumulative weight loss of 3\%, $5 \%$, and $7 \%$ at the end of the 7- to 12 -month post-index period $(\mathrm{VR}=0.88-0.95 ; P<0.05)$ versus no weight change and $16 \%-23 \%$ lower among patients with weight loss $(\mathrm{VR}=0.77-0.84 ; P<0.05)$ versus weight gain. Weight loss did not affect all-cause inpatient visits in the short term (data not shown).

\section{Effect of Weight Loss on Annual All-Cause and T2DM-Related Costs and HCRU in the Long Term}

Mean all-cause and T2DM-related annual total health care costs of the study sample were $\$ 10,589$ (prescription services $=\$ 3,277$; ED costs $=\$ 234$; inpatient costs $=\$ 2,439 ;$ outpatient costs $=\$ 4,639$ ) and $\$ 2,450$ (prescription services $=\$ 998$; ED costs $=\$ 127$; inpatient costs $=\$ 23$; outpatient costs $=\$ 1,303$ ), respectively (Table 3). After controlling for changes in timevarying confounders including Alc using SNMM, weight loss was associated with significantly lower all-cause and T2DM-related annual total health care costs. All-cause annual total health care costs were 5\%-10\% lower (CR=0.90-0.95; $P<0.05$ ) among patients with weight loss (resulting in $\sim \$ 500$, 
Effect of Weight Change on Economic Outcomes Among Persons with

Type 2 Diabetes Mellitus in the United States: Beyond Glycemic Control

\section{FIGURE 1 Sample Selection and Resulting Patient Counts}

Patients with evidence of $\geq 2$ diagnosis codes for T2DM or evidence of $\geq 1$ diagnosis code for T2DM and use of OADs or GLP-1RAs, with at most one T1DM code between January 1, 2010, and December 31, 2014 $\mathrm{N}=3,890,239$

\begin{tabular}{|c} 
Among patients excluded using the criterion above, the following inclusion criterion was applied: \\
Evidence of insulin use only plus greater number of T2DM codes than T1DM codes in pre-index period \\
Continuous enrollment in the health plan for $\geq 180$ days before index date \\
(6-month pre-index or baseline period) \\
$n=2,240,542$
\end{tabular}

No evidence of $\geq 1$ diagnosis/procedure code for gestational diabetes, bariatric surgery, pregnancy, total pancreatic failure, acute or chronic pancreatitis, stage 5 ESRD, dialysis/renal replacement therapy, feeding difficulty, liver cirrhosis, cancer, or malignancy at any time during study period $n=1,000,825$

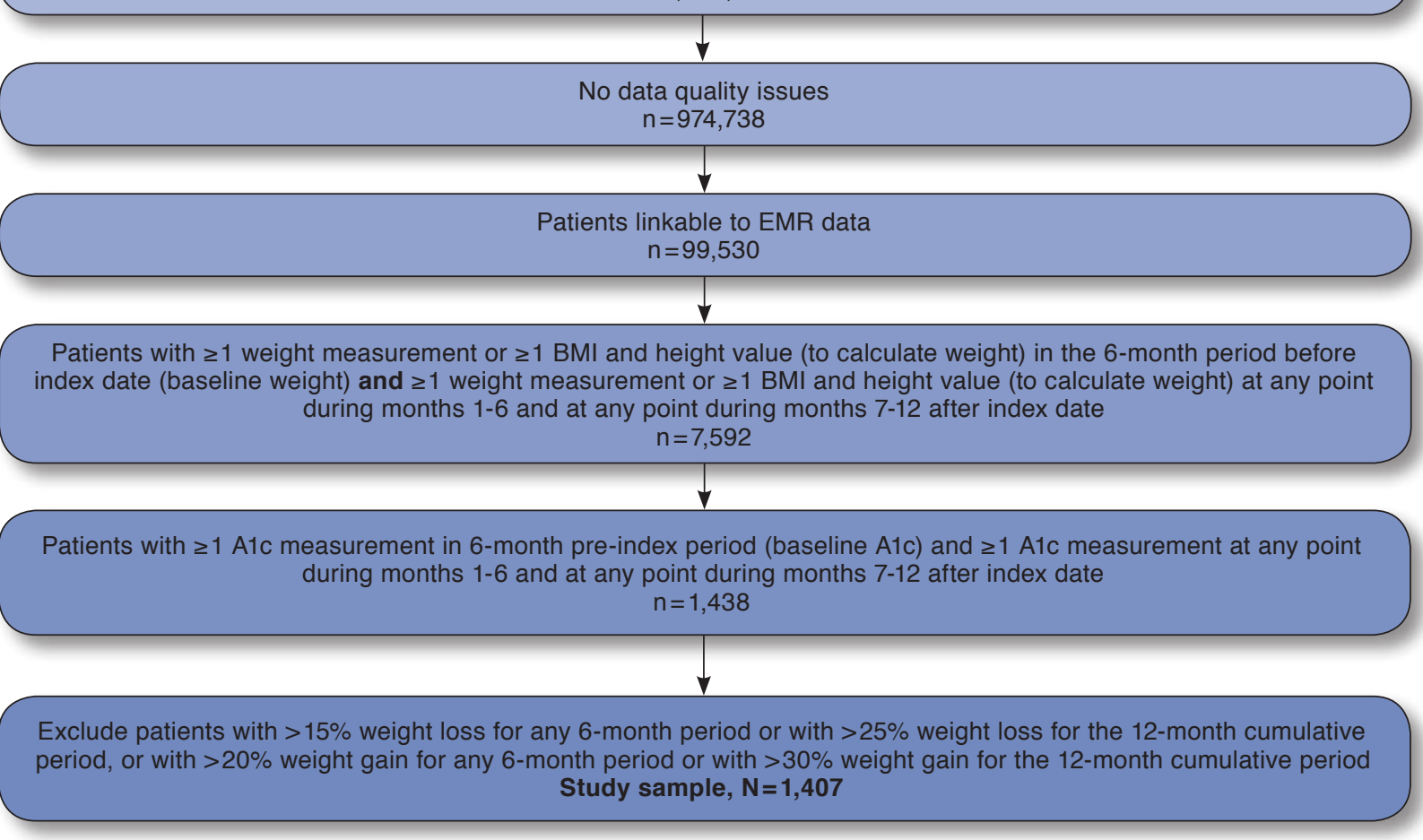

Alc=hemoglobin A1c; BMI =body mass index; EMR = electronic medical record; ESRD = end-stage renal disease; GLP-1RA=glucagon-like peptide-1 receptor agonist $O A D=$ oral antidiabetic drug; T1DM = type 1 diabetes mellitus; T2DM = type 2 diabetes mellitus. 


\section{TABLE 1 Baseline Demographic and Clinical Characteristics of the Study Sample}

\begin{tabular}{|c|c|c|c|c|c|}
\hline Characteristics & \multicolumn{2}{|c|}{ Overall Sample $(\mathrm{N}=1,407)$} & Characteristics & \multicolumn{2}{|c|}{ Overall Sample $(\mathrm{N}=1,407)$} \\
\hline \multicolumn{3}{|l|}{ Age at index date (years) } & \multicolumn{3}{|l|}{ Comorbidities of interest (n, \%) } \\
\hline Mean & 55.2 & & Dyslipidemia, hypertriglyceridemia & 877 & 62.3 \\
\hline SD & 9.3 & & Gastroesophageal reflux disease & 144 & 10.2 \\
\hline Median & 56.0 & & Hypertension & 853 & 60.6 \\
\hline \multicolumn{3}{|l|}{ Gender (n, \%) } & Obesity & 202 & 14.4 \\
\hline Male & 777 & 55.2 & Obstructive sleep apnea & 170 & 12.1 \\
\hline Female & 630 & 44.8 & Prediabetes & 382 & 27.1 \\
\hline \multicolumn{3}{|l|}{ U.S. census region (n, \%) } & Sleep apnea & 179 & 12.7 \\
\hline Northeast & 737 & 52.4 & \multicolumn{3}{|l|}{ Concomitant medications (n, \%) } \\
\hline Midwest & 297 & 21.1 & Antihypertensive medications & 772 & 54.9 \\
\hline South & 293 & 20.8 & Lipid-lowering therapy & 744 & 52.9 \\
\hline West & 80 & 5.7 & Other cardiovascular medications & 128 & 9.1 \\
\hline \multicolumn{3}{|l|}{ Health plan type (n, \%) } & Sedatives, hypnotics & 115 & 8.2 \\
\hline Consumer-directed health plan & 4 & 03 & Antibiotics & 440 & 31.3 \\
\hline Health maintenance organization & 266 & $\frac{100}{0.2}$ & NSAIDs & 227 & 16.1 \\
\hline Indemnity & 68 & 10.9 & Neuropathy treatment & 326 & 23.2 \\
\hline Point-of-service & 47 & 3.3 & \multicolumn{3}{|c|}{ Number of pre-index antidiabetic classes used } \\
\hline Preferred provider organization & 1,022 & 72.6 & Mean & 0.7 & \\
\hline \multicolumn{3}{|l|}{ Primary payer type (n, \%) } & SD & 1.0 & \\
\hline Commercial & 660 & 46.9 & Median & 0.0 & \\
\hline Medicaid & 1 & 0.1 & \multicolumn{3}{|l|}{ BMI $\left(\mathrm{kg} / \mathrm{m}^{2}\right)$} \\
\hline Medicare Risk & 18 & 1.3 & Mean & 35.0 & \\
\hline Self-insured & 728 & 51.7 & SD & 6.7 & \\
\hline \multicolumn{3}{|l|}{ Physician specialty at index (n, \%) } & Median & 34.2 & \\
\hline General practice/family practice & 442 & 31.4 & \multicolumn{3}{|l|}{ Weight $(\mathrm{kg})$} \\
\hline Internal medicine & 344 & 24.4 & Mean & 102.2 & \\
\hline Endocrinology & 37 & 2.6 & SD & 22.9 & \\
\hline Other & 481 & 34.2 & Median & 99.7 & \\
\hline Unknown & 103 & 7.3 & \multicolumn{3}{|l|}{ Alc (\%) } \\
\hline \multicolumn{3}{|c|}{ CCI score (excluding T1DM and T2DM) } & Mean & 7.4 & \\
\hline Mean & 0.3 & & SD & 1.6 & \\
\hline $\mathrm{SD}$ & 0.7 & & \multicolumn{3}{|l|}{ Alc, n (\%) } \\
\hline Median & 0.0 & & $<6.0 \%$ & 112 & 8.0 \\
\hline \multicolumn{3}{|c|}{ Adapted Diabetes Complications Severity Index score } & $6.0 \%-6.9 \%$ & 611 & 43.4 \\
\hline Mean & 0.4 & & $7.0 \%-7.9 \%$ & 378 & 26.9 \\
\hline SD & 0.9 & & $8.0 \%-9.0 \%$ & 135 & 9.6 \\
\hline Median & 0.0 & & $>9.0 \%$ & 171 & 12.2 \\
\hline
\end{tabular}

aList of comorbidities: anorexia; asthma; cachexia; chronic kidney disease and related renal conditions; chronic nonalcoholic liver disease (includes nonalcoholic liver disease and nonalcoholic steatohepatitis); congestive heart failure; connective tissue/rheumatic disease; chronic obstructive pulmonary disease; Cushing syndrome; depression; diabetes with other coma; dyslipidemia and hypertriglyceridemia; dyspepsia; epilepsy; gallbladder disease; gastroesophageal reflux disease; human immunodeficiency virus/acquired immunodeficiency syndrome; hypertension; hypoglycemia; inflammatory bowel diseases (Crohn's disease or ulcerative colitis); liver disease; metabolic syndrome; myocardial infarction; nutritional deficiencies (except for vitamin deficiency); obesity; obesity hypoventilation syndrome; obstructive sleep apnea; osteoarthritis; osteoporosis; peptic ulcer; pneumonia; Prader-Willi syndrome; prediabetes; renal disease; severe psychiatric disorder (schizophrenia, other psychotic disorder, or bipolar disorder); sleep apnea; and stroke.

Alc =hemoglobin A1c; BMI = body mass index; CCI=Charlson Comorbidity Index; NSAID = nonsteroidal anti-inflammatory drug; SD=standard deviation; T1DM= type 1 diabetes mellitus; T2DM = type 2 diabetes mellitus.

$\$ 800$, and $\$ 1,100$ in savings, respectively) versus no weight change. Greater magnitude of weight loss resulted in greater savings. All-cause annual total health care costs were 15\%-20\% lower $(\mathrm{CR}=0.80-0.85 ; \mathrm{P}<0.05)$ among patients with weight loss versus weight gain (resulting in up to $\sim \$ 2,000$ in savings).
Differences in annual all-cause total health care costs can be attributed to differences in all-cause outpatient costs, which were significantly lower among patients with weight loss versus no weight change and among patients with weight loss versus weight gain. T2DM-related annual total costs were 7\%-19\% 
Effect of Weight Change on Economic Outcomes Among Persons with

Type 2 Diabetes Mellitus in the United States: Beyond Glycemic Control

\section{TABLE 2}

All-Cause and T2DM-Related HCRU of the Study Sample

\begin{tabular}{|c|c|c|c|c|c|c|c|c|c|c|}
\hline \multirow[b]{2}{*}{ Characteristics } & & & \multicolumn{4}{|c|}{ Evaluation Period } & \multicolumn{4}{|c|}{ Outcomes Measurement Period } \\
\hline & \multicolumn{2}{|c|}{$\begin{array}{c}\text { Baseline } \\
(\mathrm{N}=1,407)\end{array}$} & \multicolumn{2}{|c|}{$\begin{array}{l}\text { 1-6 Months } \\
\text { Post-Index } \\
(\mathrm{N}=1,407)\end{array}$} & \multicolumn{2}{|c|}{$\begin{array}{c}\text { 7-12 Months } \\
\text { Post-Index } \\
(\mathrm{N}=1,407)\end{array}$} & \multicolumn{2}{|c|}{$\begin{array}{l}\text { 13-18 Months } \\
\text { Post-Index } \\
(\mathrm{N}=1,407)\end{array}$} & \multicolumn{2}{|c|}{$\begin{array}{l}\text { 13-24 Months } \\
\text { Post-Index } \\
(\mathrm{N}=1,407)\end{array}$} \\
\hline \multicolumn{11}{|c|}{ All-cause visits/services used } \\
\hline \multicolumn{11}{|c|}{ Pharmacy (including all pharmacy prescriptions and infusion administrations) } \\
\hline Patients with pharmacy scripts (n, \%) & 1,289 & 91.6 & 1,346 & 95.7 & 1,342 & 95.4 & 1,346 & 95.7 & 1,364 & 96.9 \\
\hline Mean & 15.6 & & 19.4 & & 18.6 & & 18.4 & & 37.0 & \\
\hline SD & 14.0 & & 14.6 & & 14.7 & & 14.2 & & 27.7 & \\
\hline Median & 12.0 & & 16.0 & & 15.0 & & 15.0 & & 30.0 & \\
\hline \multicolumn{11}{|l|}{ ED visits } \\
\hline Patients with visits (n, \%) & 135 & 9.6 & 168 & 11.9 & 153 & 10.9 & 120 & 8.5 & 218 & 15.5 \\
\hline Mean & 0.1 & & 0.2 & & 0.1 & & 0.1 & & 0.2 & \\
\hline SD & 0.4 & & 0.5 & & 0.5 & & 0.4 & & 0.6 & \\
\hline Median & 0.0 & & 0.0 & & 0.0 & & 0.0 & & 0.0 & \\
\hline \multicolumn{11}{|l|}{ Inpatient visits } \\
\hline Patients with visits $(\mathrm{n}, \%)$ & 50 & 3.6 & 81 & 5.8 & 47 & 3.3 & 51 & 3.6 & 98 & 7.0 \\
\hline Mean & 0.0 & & 0.1 & & 0.0 & & 0.0 & & 0.1 & \\
\hline $\mathrm{SD}$ & 0.2 & & 0.3 & & 0.3 & & 0.3 & & 0.4 & \\
\hline Median & 0.0 & & 0.0 & & 0.0 & & 0.0 & & 0.0 & \\
\hline \multicolumn{11}{|c|}{ Average length of stay among patients with inpatient visits } \\
\hline Mean & 3.2 & & 3.7 & & 3.6 & & 3.7 & & 3.6 & \\
\hline $\mathrm{SD}$ & 1.7 & & 2.3 & & 2.9 & & 1.8 & & 2.4 & \\
\hline Median & 3.0 & & 3.0 & & 2.0 & & 3.0 & & 3.0 & \\
\hline \multicolumn{11}{|l|}{ Outpatient visits } \\
\hline Patients with visits (n, \%) & 1,385 & 98.4 & 1,405 & 99.9 & 1,400 & 99.5 & 1,368 & 97.2 & 1,398 & 99.4 \\
\hline Mean & 21.3 & & 25.3 & & 22.6 & & 20.5 & & 41.0 & \\
\hline SD & 18.2 & & 20.2 & & 19.4 & & 19.3 & & 33.4 & \\
\hline Median & 16.0 & & 20.0 & & 17.0 & & 15.0 & & 32.0 & \\
\hline \multicolumn{11}{|c|}{ T2DM-related visits/services used } \\
\hline \multicolumn{11}{|c|}{ Pharmacy (including all pharmacy prescriptions and infusion administrations) } \\
\hline Patients with pharmacy scripts (n, \%) & 706 & 50.2 & 1,096 & 77.9 & 1,041 & 74.0 & 1,043 & 74.1 & 1,111 & 79.0 \\
\hline Mean & 2.5 & & 4.8 & & 4.2 & & 4.1 & & 8.2 & \\
\hline SD & 4.2 & & 4.8 & & 4.5 & & 4.4 & & 8.5 & \\
\hline Median & 1.0 & & 4.0 & & 3.0 & & 3.0 & & 6.0 & \\
\hline \multicolumn{11}{|l|}{ ED visits } \\
\hline Patients with visits (n, \%) & 23 & 1.6 & 81 & 5.8 & 84 & 6.0 & 50 & 3.6 & 95 & 6.8 \\
\hline Mean & 0.0 & & 0.1 & & 0.1 & & 0.0 & & 0.1 & \\
\hline SD & 0.2 & & 0.3 & & 0.3 & & 0.3 & & 0.4 & \\
\hline Median & 0.0 & & 0.0 & & 0.0 & & 0.0 & & 0.0 & \\
\hline \multicolumn{11}{|l|}{ Inpatient visits } \\
\hline Patients with visits (n, \%) & 3 & 0.2 & 11 & 0.8 & 8 & 0.6 & 8 & 0.6 & 13 & 0.9 \\
\hline Mean & 0.0 & & 0.0 & & 0.0 & & 0.0 & & 0.0 & \\
\hline SD & 0.0 & & 0.1 & & 0.1 & & 0.1 & & 0.1 & \\
\hline Median & 0.0 & & 0.0 & & 0.0 & & 0.0 & & 0.0 & \\
\hline Average length of stay among patients & ent visit & & & & & & & & & \\
\hline Mean & 2.7 & & 4.0 & & 2.0 & & 4.6 & & 3.3 & \\
\hline SD & 2.9 & & 4.5 & & 1.1 & & 3.3 & & 3.1 & \\
\hline Median & 1.0 & & 3.0 & & 2.0 & & 3.5 & & 2.0 & \\
\hline Outpatient visits & & & & & & & & & & \\
\hline Patients with visits (n, \%) & 518 & 36.8 & 1,393 & 99.0 & 1,299 & 92.3 & 1,189 & 84.5 & 1,309 & 93.0 \\
\hline Mean & 3.4 & & 11.3 & & 8.7 & & 7.6 & & 15.1 & \\
\hline SD & 6.4 & & 8.3 & & 7.5 & & 7.5 & & 12.4 & \\
\hline Median & 0.0 & & 10.0 & & 7.0 & & 6.0 & & 14.0 & \\
\hline
\end{tabular}


Effect of Weight Change on Economic Outcomes Among Persons with

Type 2 Diabetes Mellitus in the United States: Beyond Glycemic Control

TABLE 3 All-Cause and T2DM-Related Costs of the Study Sample

\begin{tabular}{|c|c|c|c|c|c|c|c|c|c|c|c|c|c|c|c|}
\hline \multirow[b]{3}{*}{ Costs, $\$$} & & & & \multicolumn{6}{|c|}{ Evaluation Period } & \multicolumn{6}{|c|}{ Outcomes Measurement Period } \\
\hline & \multicolumn{3}{|c|}{ Baseline } & \multicolumn{3}{|c|}{ 1-6 Months Post-Index } & \multicolumn{3}{|c|}{ 7-12 Months Post-Index } & \multicolumn{3}{|c|}{ 13-18 Months Post-Index } & \multicolumn{3}{|c|}{ 13-24 Months Post-Index } \\
\hline & Mean & Median & SD & Mean & Median & SD & Mean & Median & SD & Mean & Median & SD & Mean & Median & SD \\
\hline \multicolumn{16}{|l|}{ All-cause costs } \\
\hline Total costs & 4,228 & 2,067 & 7,829 & 5,990 & 2,664 & 12,059 & 4,974 & 2,280 & 11,379 & 5,043 & 2,305 & 10,320 & 10,589 & 5,239 & 26,341 \\
\hline Prescription costs & 1,307 & 613 & 2,827 & 1,596 & 823 & 3,830 & 1,592 & 850 & 3,449 & 1,578 & 815 & 3,359 & 3,277 & 1,713 & 6,603 \\
\hline ED costs & 90 & 0 & 481 & 152 & 0 & 719 & 114 & 0 & 608 & 125 & 0 & 786 & 234 & 0 & 1,124 \\
\hline Inpatient costs & 760 & 0 & 5,094 & 1,481 & 0 & 8,382 & 919 & 0 & 7,178 & 1,011 & 0 & 6,691 & 2,439 & 0 & 22,971 \\
\hline Outpatient costs & 2,071 & 939 & 3,585 & 2,761 & 1,326 & 4,700 & 2,349 & 1,002 & 5,194 & 2,329 & 958 & 5,172 & 4,639 & 2,359 & 7,379 \\
\hline \multicolumn{16}{|l|}{ T2DM-related costs } \\
\hline Total costs & 550 & 10 & 2,119 & 1,498 & 783 & 2,856 & 1,251 & 495 & 3,941 & 1,211 & 472 & 3,878 & 2,450 & 1,004 & 4,998 \\
\hline Prescription costs & 267 & 0 & 642 & 433 & 105 & 769 & 456 & 55 & 971 & 471 & 51 & 915 & 998 & 133 & 1,925 \\
\hline ED costs & 16 & 0 & 175 & 80 & 0 & 565 & 58 & 0 & 429 & 62 & 0 & 647 & 127 & 0 & 938 \\
\hline Inpatient costs & 5 & 0 & 162 & 10 & 0 & 274 & 1 & 0 & 19 & 3 & 0 & 43 & 23 & 0 & 726 \\
\hline Outpatient costs & 262 & 0 & 1,781 & 976 & 501 & 2,558 & 737 & 312 & 3,669 & 675 & 287 & 3,629 & 1,303 & 614 & 4,063 \\
\hline
\end{tabular}

$E D=$ emergency department; $S D=$ standard deviation; $T 2 D M=$ type 2 diabetes mellitus.

lower $(\mathrm{CR}=0.81-0.93 ; \mathrm{P}<0.05)$ among patients with weight loss (resulting in $\sim \$ 200,300$, and $\$ 400$ in savings, respectively) versus no weight change. A greater magnitude of weight loss resulted in greater savings: T2DM-related annual total costs were 23\%-33\% lower (CR=0.67-0.77; $P<0.05)$ among patients with weight loss versus weight gain (resulting in up to $\sim$ \$800 savings). Weight loss did not affect all-cause prescription, inpatient, and ED costs in the long term. Overall, weight loss in T2DM resulted in significant reductions in all-cause and T2DM-related annual total health care costs, irrespective of the pattern in which weight loss occurred (Table 4).

During the 12-month follow-up period, the majority of T2DM patients used prescription services (all-cause $=96.9 \%$; T2DM-related $=79.0 \%$ ) and had $\geq 1$ annual outpatient visit (all-cause $=99.4 \%$; T2DM-related $=93.0 \%$ ). Refer to Table 2 for additional details. After controlling for changes in time-varying confounders including Alc using SNMMs, weight loss did not affect annual all-cause inpatient and ED visits. However, annual all-cause outpatient visits were 5\%-13\% lower (VR=0.87-0.95; $P<0.05$ ) among patients with weight loss versus no weight change and $16 \%-23 \%$ lower ( $\mathrm{VR}=0.77-0.84 ; P<0.05)$ among patients with weight loss versus weight gain (data not shown).

\section{Discussion}

In this study, controlling for time-varying covariates resulted in significant reductions in all-cause and T2DM-related annual total health care costs, irrespective of weight loss pattern. Also, weight loss significantly decreased T2DM-related total health care costs in the short term. Previous studies, such as retrospective database analysis by Bell et al. (2014), evaluated the effect of weight change (weight loss $>3 \%$ or weight gain $>3 \%$ vs. weight neutral [change $\leq 3 \%$ ]) among 2,110 T2DM patients in the first 6 months after initiating noninsulin antidiabetic medication on health care costs incurred in the following 12 months. ${ }^{22}$ That study reported that the weight-loss cohort, compared with the weight-neutral cohort, had significantly lower annual all-cause $(\$ 2,200)$ and T2DM-related total costs ( $\$ 440 ; P<0.05$ for both), and weight gain was found to be associated with significantly higher $(\$ 3,400)$ all-cause annual total costs. ${ }^{22}$ Mukherjee et al. (2016) reported that a decrease in weight change over a 6-month period was associated with lower T2DM-related costs $(P=0.039)$ over the subsequent 12-month period. ${ }^{25}$ Yu et al. (2007) conducted a retrospective cohort study using health maintenance organization data on 458 T2DM patients from 1997-2005 and reported that every 1 percentage point of weight loss over a 6-month period was associated with a $3.6 \%$ decrease in all-cause total costs $(\$ 256$; $P<0.05)$ and a $5.8 \%$ decrease $(\$ 131 ; P<0.01)$ in T2DM-related total costs in the subsequent 12 -month period. ${ }^{28}$ Findings from this current study are, therefore, consistent with previous evidence linking weight loss among T2DM patients with significant savings in health care costs and reduced resource use. Additionally, in this study, the effect of weight loss was assessed after adjusting for changes in Alc to evaluate the incremental effect of weight loss. To our knowledge, this is the first study to determine the savings in health care costs and reduced resource use attributable to weight loss, beyond achieving glycemic control.

We observed consistent results as previous U.S.-based studies even though the patients were at different stages in their treatment pathway. For example, Bell et al. only included patients receiving noninsulin antidiabetic medications, and Mukherjee et al. only included patients who added to or switched from metformin monotherapy-where both populations were possibly earlier in the disease course, before complications occurred-whereas our study included patients receiving any antidiabetic medication class (OADs, GLP-1RAs, or insulin) without any medication washout period, thus, 
Effect of Weight Change on Economic Outcomes Among Persons with

Type 2 Diabetes Mellitus in the United States: Beyond Glycemic Control

Effect of Weight Loss on Health Care Costs

\begin{tabular}{|c|c|c|c|c|c|c|c|c|c|c|}
\hline & \multicolumn{2}{|c|}{ Weight Loss Pattern } & \multicolumn{2}{|c|}{$\begin{array}{c}\text { Short-Term T2DM-Related } \\
\text { Total Costs } \\
\text { (6 Months Follow-up) } \\
\end{array}$} & \multicolumn{2}{|c|}{$\begin{array}{c}\text { Long-Term T2DM-Related } \\
\text { Total Costs } \\
\text { (12 Months Follow-up) } \\
\end{array}$} & \multicolumn{2}{|c|}{$\begin{array}{c}\text { Long-Term } \\
\text { All-Cause } \\
\text { Outpatient Costs } \\
\text { (12 Months Follow-up) }\end{array}$} & \multicolumn{2}{|c|}{$\begin{array}{c}\text { Long-Term } \\
\text { All-Cause } \\
\text { Total Costs } \\
\text { (12 Months Follow-up) }\end{array}$} \\
\hline & $\begin{array}{c}1-6 \text { Months } \\
\%\end{array}$ & $\begin{array}{c}\text { 7-12 Months } \\
\%\end{array}$ & $\begin{array}{l}\text { Savings per } \\
\text { Patient vs. } \\
\text { No Weight } \\
\text { Change, } \$\end{array}$ & $\begin{array}{l}\text { Savings } \\
\text { per Patient } \\
\text { vs. Weight } \\
\text { Gaina }^{\mathrm{a}}, \$\end{array}$ & $\begin{array}{l}\text { Savings per } \\
\text { Patient vs. } \\
\text { No Weight } \\
\text { Change, \$ }\end{array}$ & $\begin{array}{l}\text { Savings } \\
\text { per Patient } \\
\text { vs. Weight } \\
\text { Gaina }^{\mathrm{a}}, \$\end{array}$ & $\begin{array}{l}\text { Savings per } \\
\text { Patient vs. } \\
\text { No Weight } \\
\text { Change, \$ }\end{array}$ & $\begin{array}{l}\text { Savings } \\
\text { per Patient } \\
\text { vs. Weight } \\
\text { Gaina }{ }^{\mathrm{a}}, \$\end{array}$ & $\begin{array}{l}\text { Savings per } \\
\text { Patient vs. } \\
\text { No Weight } \\
\text { Change, } \$\end{array}$ & $\begin{array}{c}\text { Savings } \\
\text { per Patient } \\
\text { vs. Weight } \\
\text { Gain }{ }^{\mathrm{a}}, \$\end{array}$ \\
\hline \multirow{3}{*}{$\begin{array}{l}3 \% \text { weight } \\
\text { loss }\end{array}$} & 3 & 0 & 81.30 & $232.50^{\mathrm{b}}$ & $215.53^{b}$ & $597.55^{b}$ & 187.28 & $656.82^{\mathrm{b}}$ & $486.54^{b}$ & $1,539.44^{b}$ \\
\hline & 0 & 3 & 63.29 & $216.91^{b}$ & $162.48^{b}$ & $553.56^{b}$ & $245.32^{b}$ & $708.74 b$ & $489.23^{b}$ & $1,541.85 b$ \\
\hline & 1.5 & 1.5 & $72.33^{b}$ & $224.74^{b}$ & $189.16^{b}$ & $575.69^{b}$ & $216.39^{b}$ & $682.87^{b}$ & $487.88^{b}$ & $1,540.65^{b}$ \\
\hline \multirow{3}{*}{$\begin{array}{l}5 \% \text { weight } \\
\text { loss }\end{array}$} & 5 & 0 & 132.44 & $276.80^{b}$ & $348.59 b$ & $707.86^{b}$ & 307.91 & $764.73 \mathrm{~b}$ & $798.41^{b}$ & $1,818.81^{b}$ \\
\hline & 0 & 5 & 103.63 & $251.85^{b}$ & $264.76^{b}$ & $638.36^{b}$ & $401.61^{b}$ & $848.55^{b}$ & $802.76^{b}$ & $1,822.71^{b}$ \\
\hline & 2.5 & 2.5 & $118.13^{b}$ & $264.41^{b}$ & $307.08^{b}$ & $673.45^{b}$ & $355.02^{b}$ & $806.87^{b}$ & $800.59^{b}$ & $1,820.76^{b}$ \\
\hline \multirow{3}{*}{$\begin{array}{l}7 \% \text { weight } \\
\text { loss }\end{array}$} & 7 & 0 & 181.27 & $319.09 \mathrm{~b}$ & $473.72^{b}$ & $811.60^{\mathrm{b}}$ & 425.27 & $869.71^{b}$ & $1,100.66^{b}$ & $2,089.56^{b}$ \\
\hline & 0 & 7 & 142.56 & $285.56^{b}$ & $362.48^{b}$ & $719.38^{b}$ & $552.35^{b}$ & $983.39 \mathrm{~b}$ & $1,106.56^{b}$ & $2,094.85^{b}$ \\
\hline & 3.5 & 3.5 & $162.09^{b}$ & $302.48^{b}$ & $418.86^{b}$ & $766.12^{b}$ & $489.30^{\mathrm{b}}$ & $926.99^{b}$ & $1,103.61^{b}$ & $2,092 \cdot 20^{b}$ \\
\hline
\end{tabular}

Note: Only significant findings were included in this table. Costs calculated as: Mean total cost-(cost ratio in the SNMM $\times$ mean total cost).

aThose who gained 3.5\% in 1-6 months and gained another 3.5\% in 7-12 months post-index.

${ }^{b} P<0.05$.

SNMM = structural nested mean model; T2DM = type 2 diabetes mellitus

analyzing a more heterogeneous and more advanced T2DM population. $^{22,25}$

In addition, all-cause annual outpatient visits and costs were significantly lower among patients with weight loss versus those with no weight change or weight gain. Lower Alc levels and better control of cardiovascular risk factors and diabetesrelated comorbidities and complications among patients with weight loss may decrease the need for physicians to closely monitor these patients, thereby decreasing outpatient health care utilization and costs. ${ }^{18,25}$ An unexpected finding from our study was that ED visits in the short term were significantly higher among patients with weight loss compared with no weight change and weight gain. T2DM patients with obesity and hypertension are reported to have significantly more ED visits compared with those with T2DM alone. ${ }^{33}$

Finally, irrespective of the timing or pattern in which weight loss occurred over the study period, losing weight was associated with significant reductions in all-cause and T2DM-related annual total health care costs.

Our study adds to the current body of literature and further strengthens the importance of weight loss and maintenance of weight loss in management of patients with T2DM beyond glycemic improvements vis-à-vis Alc lowering. Because our study quantifies the benefits associated with weight loss, findings can help health care decision makers with cost-containment strategies that incorporate more than drug acquisition factors. Guidelines recommend intensive intervention programs and frequent follow-up for weight reduction among T2DM patients who are overweight and obese. ${ }^{6,12}$ However, more than $80 \%$ of patients with T2DM continue to be overweight or obese. ${ }^{1}$ There is clearly an unmet need for weight management among T2DM patients. Although intensive programs may help achieve weight loss goals in clinical trials, it is difficult to adhere to and deliver these programs in the real world. ${ }^{34,35}$ Per American Association of Clinical Endocrinologists guidelines, adding medication to lifestyle change for chronic weight loss should be considered among patients who are unable to lose weight or maintain their weight loss using diet and exercise alone. ${ }^{12,34}$

Our study findings also have clinical implications. Although Alc control is often the primary therapeutic goal for patients with T2DM, there is a need to recognize the importance of avoiding medication-related weight gain among these patients and overall cardiovascular risk reduction. ${ }^{12}$ As different antidiabetic medications have different weight change profiles, previous studies and guidelines suggest that physicians should individualize medication therapy based on each patient's weight loss goals, consider the effect of antidiabetic agents on weight (in addition to clinical effectiveness) among patients receiving combination therapy, and opt for weight-neutral medications if possible. ${ }^{4,6,12,35,36}$ This may also potentially affect medication adherence, per previous evidence that T2DM patients who lose weight on a treatment regimen are more likely to adhere to their regimen compared with patients who gain weight with their medication. ${ }^{15}$ According to our study, even a modest weight loss (3\%) can result in significantly lower annual all-cause and T2DM-related health care costs. Focusing on weight loss early in the disease progression pathway may enable patients to reap advantages from early lines of therapy that provide good Alc control in addition to weight loss benefits. ${ }^{25}$ 


\section{Limitations}

The results of this study should be viewed in the context of potential limitations. First, claims and EMR databases are not primarily designed for research purposes. Internal validity is typically not good enough to infer causality due to the lack of randomization and to make a strong conclusion regarding whether measurable or unmeasurable factors affect the outcomes of interest. External validity is not high due to the fact that the study employs small samples and may not be generalizable to the other populations like uninsured patients.

Second, the analytic focus of this study was on patients who met continuous observation criteria (180 days pre-index and 720 days post-index), with a potential to eliminate subjects who may have had different weight change patterns coincident with observation patterns. Also, patients with $>15 \%$ weight loss for any 6-month period or with $>25 \%$ weight loss for 12-month cumulative period were excluded from this study, which is possible among patients with very low-calorie diets. This may influence generalizability of the study findings to this unique group of patients.

Third, because of the time-varying nature of weight, for patients with $>1$ weight measurement in both 6-month periods, the measurement closest to the end of the time interval was considered the post-index weight instead of the average weight. Also, data entry errors may exist at the site of care, contributing to survey bias. The reverse trend was observed in ED visits, where a higher percentage of visits with weight loss versus no weight change or weight gain can be because of the low sample size of patients with these visits.

Finally, this study could only evaluate a few patterns of weight change, and other weight change patterns may have a different effect on annual health care costs and HCRU.

\section{Conclusions}

Weight loss among patients with T2DM resulted in significant reductions in all-cause and T2DM-related annual total health care costs compared with no weight change or weight gain, irrespective of weight loss pattern. Greater weight loss resulted in greater cost savings. This study helps link weight loss to outcomes that matter to health care decision makers and will help reinforce the value of weight loss in T2DM. Future research should evaluate the effect of weight loss, beyond glycemic control, on economic outcomes using longer follow-up periods.

\section{Authors}

SWAPNA KARKARE, MS; JINGSONG LU, MS; and MITCH DEKOVEN, MHSA, IQVIA, Real World Insights, Falls Church, Virginia. MOSHE FRIDMAN, PhD, AMF Consulting, Los Angeles, California. TAM DANG-TAN, PhD; B. GABRIEL SMOLARZ, MD, MS, FACE; and NEERAJ N. IYER, PhD, Novo Nordisk, Plainsboro, New Jersey.

AUTHOR CORRESPONDENCE: Neeraj N. Iyer, PhD, Director, Value Evidence \& Outcomes, Clinical, Medical \& Regulatory Affairs, Novo Nordisk, 800 Scudders Mill Rd., Plainsboro, NJ 08536.

Tel.: 609.786.4899; E-mail: nriy@novonordisk.com.

\section{DISCLOSURES}

This study was funded by Novo Nordisk. Dang-Tan, Smolarz, and Iyer are employees of Novo Nordisk. Karkare and DeKoven (employees of IQVIA) and Fridman (employed by AMF Consulting) were contracted by Novo Nordisk to conduct this study. Fridman also reports personal fees from Shire, GSK and CSL Behring, outside of the submitted work. Lu, an employee of IQVIA, accessed the database and conducted the statistical analysis for this study.

\section{REFERENCES}

1. National Center for Chronic Disease Prevention and Health Promotion, Division of Diabetes Translation. National diabetes statistics report, 2017. Centers for Disease Control and Prevention. Available at: https://www.cdc. gov/diabetes/pdfs/data/statistics/national-diabetes-statistics-report.pdf. Accessed January 13, 2019.

2. American Diabetes Association. Economic costs of diabetes in the U.S. in 2017. Diabetes Care. 2018;41(5):917-28

3. American Diabetes Association. Improving care and promoting health in populations: standards of medical care in diabetes-2018. Diabetes Care. 2018;41(Suppl 1):S7-S12.

4. American Diabetes Association. Economic costs of diabetes in the U.S. in 2012. Diabetes Care. 2013;36(4):1033-46.

5. Inzucchi SE, Bergenstal RM, Buse JB, et al. Management of hyperglycemia in type 2 diabetes, 2015: a patient-centered approach: update to a position statement of the American Diabetes Association and the European Association for the Study of Diabetes. Diabetes Care. 2015;38:140-49.

6. Centers for Disease Control and Prevention. Prevalence of overweight and obesity among adults with diagnosed diabetes-United States 1988-1994 and 1999-2002. Morbid Mortal Wkly Rep. 2004;53(45):1066-68. Available at: https://www.cdc.gov/mmwr/preview/mmwrhtml/mm5345a2.htm. Accessed January 13, 2019.

7. Anderson JW, Kendall CW, Jenkins DJ. Importance of weight management in type 2 diabetes: review with meta-analysis of clinical studies. J Am Coll Nutr. 2003;2:331-39.

8. American Diabetes Association. Standards of medical care for patients with diabetes mellitus. Diabetes Care. 2003;26(Suppl 1):S33-S50.

9. Van Gaal LF, Mertens IL, De Block CE. Mechanisms linking obesity with cardiovascular disease. Nature. 2006;444:875-80.

10. Franz MJ, Boucher JL, Rutten-Ramos S, VanWormer JJ. Lifestyle weightloss intervention outcomes in overweight and obese adults with type 2 diabetes: a systematic review and meta-analysis of randomized clinical trials. J Acad Nutr Diet. 2015;115(9):1447-63.

11. American Diabetes Association, Bantle JP, Wylie-Rosett J, et al. Nutrition recommendations and interventions for diabetes: a position statement of the American Diabetes Association. Diabetes Care. 2008;31(Suppl 1):S61-78.

12. Garber AJ, Abrahamson MJ, Barzilay JI, Blonde L et al. Consensus statement by the American Association of Clinical Endocrinologists and American College of Endocrinology on the comprehensive type 2 diabetes management algorithm-2018 executive summary. Endocr Pract. 2018;24(1):91-120.

13. Wing RR, Lang W, Wadden TA, et al. Benefits of modest weight loss in improving cardiovascular risk factors in overweight and obese individuals with type 2 diabetes. Diabetes Care. 2011;34(7):1481-86.

14. Feldstein AC, Nichols GA, Smith DH et al. Weight change in diabetes and glycemic and blood pressure control. Diabetes Care. 2008;31:1960-65. 15. Grandy S, Fox KM, Hardy E; SHIELD Study Group. Association of weight loss and medication adherence among adults with type 2 diabetes mellitus: SHIELD (Study to Help Improve Early evaluation and management of risk factors Leading to Diabetes). Curr Ther Res Clin Exp. 2013;75:77-82. 16. Look AHEAD Research Group; Wing RR. Long-term effects of a lifestyle intervention on weight and cardiovascular risk factors in individuals with type 2 diabetes mellitus: four-year results of the Look AHEAD trial. Arch Intern Med. 2010;170:1566-75.

17. Ryan DH, Yockey SR. Weight loss and improvement in comorbidity: differences at 5\%, 10\%, 15\%, and over. Curr Obes Rep. 2017;6(2):187-94 
18. Ross SA, Dzida G, Vora J, Khunti K, Kaiser M, Ligthelm RJ. Impact of weight gain on outcomes in type 2 diabetes. Curr Med Res Opin. 2011;27(7):1431-38.

19. Wilding JPH. The importance of weight management in type 2 diabetes mellitus. Int J Clin Pract. 2014;68(6):682-91.

20. Williamson DF, Thompson TJ, Thun M, Flanders D, Pamuk E, Byers T. Intentional weight loss and mortality among overweight individuals with diabetes. Diabetes Care. 2000;23(10):1499-504.

21. Blak BT, Rigney U, Sternhufvud C, Davis J, Hammar N. Weight change and health care resource use in English patients with type 2 diabetes mellitus initiating a new diabetes medication class. Int J Clin Pract. 2016;70:45-55. 22. Bell K, Parasuraman S, Shah M, et al. Economic implications of weight change in patients with type 2 diabetes mellitus. Am J Manag Care. 2014;20:e320-e9.

23. Dilla T, Valladares A, Nicolay C, Salvador J, Reviriego J, Costi M. Healthcare costs associated with change in body mass index in patients with type 2 diabetes mellitus in Spain: the ECOBIM study. Appl Health Econ Health Policy. 2012;10(6):417-30.

24. Davis WA, Bruce DG, Davis TME. Economic impact of moderate weight loss in patients with type 2 diabetes: the Fremantle Diabetes Study. Diabet Med. 2011;28:1131-35.

25. Mukherjee J, Sternhufvud C, Smith N, et al. Association between weight change, clinical outcomes, and health care costs in patients with type 2 diabetes. J Managed Care Specialty Pharm. 2016;22(5):449-66. Available at: https://www.jmcp.org/doi/10.18553/jmcp.2016.22.5.449.

26. Nichols GA, Bell K, Kimes TM, O'Keeffe-Rosetti M. Medical care costs associated with long-term weight maintenance versus weight gain among patients with type 2 diabetes. Diabetes Care. 2016;39(11):1981-86.
27. Sabale U, Bodegard J, Svennblad B, et al. Weight change patterns and health care costs in patients with newly-diagnosed type-2 diabetes in Sweden. Prim Care Diabetes. 2017;11(3):217-25.

28. Yu AP, Wu EQ, Birnbaum HG, et al. Short-term economic impact of body weight change among patients with type 2 diabetes treated with antidiabetic agents: analysis using claims, laboratory, and medical record data. Curr Med Res Opin. 2007;23(9):2157-69.

29. DerSarkissian M, Bhak RH, Huang J, et al. Maintenance of weight loss or stability in subjects with obesity: a retrospective longitudinal analysis of a real-world population. Curr Med Res Opin. 2017;33(6):1105-10.

30. Romano PS, Roos LL, Jollis JG. Adapting a clinical comorbidity index for use with ICD-9-CM administrative data: differing perspectives. J Clin Epidemiol. 1993;46(10):1075-79.

31. Chang HY, Weiner JP, Richards TM, Bleich SN, Segal JB. Validating the adapted Diabetes Complications Severity Index in claims data. Am J Manag Care. 2012;18(11):721-26

32. Almirall D, Ten Have T, Murphy SA. Structural nested mean models for assessing time-varying effect moderation. Biometrics. 2009;66(1):131-39.

33. Green AJ, Bazata DD, Fox KM, Grandy S. Quality of life, depression, and healthcare resource utilization among adults with type 2 diabetes mellitus and concomitant hypertension and obesity: a prospective survey. Cardiol Res Pract. 2012;2012:404107.

34. Anderson DA, Wadden TA. Treating the obese patient. Suggestions for primary care practice. Arch Fam Med. 1999;8(2):156-67.

35. Van Gaal L, Scheen A. Weight management in type 2 diabetes: current and emerging approaches to treatment. Diabetes Care. 2015;38(6):1161-72. 36. Carls GS, Tan R, Zhu JY. Real-world weight change among patients treated with glucagon-like peptide-1 receptor agonist, dipeptidyl peptidase-4 inhibitor and sulfonylureas for type 2 diabetes and the influence of medication adherence. Obes Sci Pract. 2017;3(3):342-51.

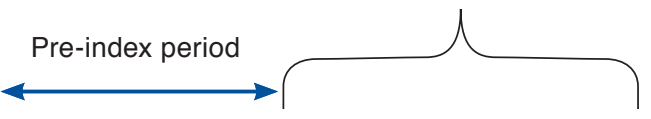

Post-index period

December 31, 2014

December 31, 2016

July 1, 2009

January 1, 2010

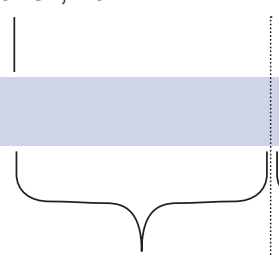

1- to 6-month

post-index perio

to evaluate weight,

A1c, HCRU,

and costs to evaluate baseline

characteristics (including

baseline weight and $\mathrm{A} 1 \mathrm{C}$ ) and costs 